\title{
Activities-specific balance confidence scale for predicting future falls in Indian older adults
}

This article was published in the following Dove Press journal:

Clinical Interventions in Aging

10 April 2017

Number of times this article has been viewed

Jamal Ali Moiz'

Vishal Bansal ${ }^{2}$

Majumi M Noohu'

Shailendra Nath Gaur ${ }^{3}$

Mohammad Ejaz Hussain'

Shahnawaz Anwer ${ }^{4,5}$

Ahmad Alghadir ${ }^{4}$

'Centre for Physiotherapy and

Rehabilitation Sciences, Jamia Millia Islamia, New Delhi, India; '2Department of Physiology, ${ }^{3}$ Department of Respiratory Medicine, Vallabhbhai Patel Chest Institute, University of Delhi, Delhi, India; ${ }^{4}$ Rehabilitation Research Chair, College of Applied Medical Sciences, King Saud University, Riyadh, Saudi Arabia; ${ }^{5}$ Department of Musculoskeletal Science, Dr D.Y. Patil College of Physiotherapy, Dr D.Y. Patil Vidyapeeth, Pune, India
Correspondence: Mohammad Ejaz Hussain

Centre for Physiotherapy and Rehabilitation Sciences, Jamia Millia Islamia, New Delhi I I0025, India

Tel +9| || 2698 |7|7

Email ehusain@jmi.ac.in
Background: Activities-specific balance confidence (ABC) scale is a subjective measure of confidence in performing various ambulatory activities without falling or experiencing a sense of unsteadiness.

Objective: This study aimed to examine the ability of the Hindi version of the ABC scale (ABC-H scale) to discriminate between fallers and non-fallers and to examine its predictive validity for prospective falls.

Design: This was a prospective cohort study.

Materials and methods: A total of 125 community-dwelling older adults ( 88 were men) completed the ABC-H scale. The occurrence of falls over the follow-up period of 12 months was recorded. Discriminative validity was analyzed by comparing the total $\mathrm{ABC}-\mathrm{H}$ scale scores between the faller and non-faller groups. A receiver operating characteristic curve analysis and a logistic regression analysis were used to examine the predictive accuracy of the ABC-H scale. Results: The mean ABC-H scale score of the faller group was significantly lower than that of the non-faller group $(52.6 \pm 8.1$ vs $73.1 \pm 12.2 ; P<0.001)$. The optimal cutoff value for distinguishing faller and non-faller adults was $\leq 58.13$. The sensitivity, specificity, area under the curve, and positive and negative likelihood ratios of the cutoff score were $86.3 \%, 87.3 \%, 0.91(P<0.001)$, 6.84 , and 0.16 , respectively. The percentage test accuracy and false-positive and false-negative rates were $86.87 \%, 12.2 \%$, and $13.6 \%$, respectively. A dichotomized total ABC-H scale score of $\leq 58.13 \%$ (adjusted odds ratio $=0.032,95 \%$ confidence interval $=0.004-0.25, P=0.001$ ) was significantly related with future falls.

Conclusion: The ABC-H scores were significantly and independently related with future falls in the community-dwelling Indian older adults. The ability of the ABC-H scale to predict future falls was adequate with high sensitivity and specificity values.

Keywords: aged, balance, cross-cultural adaptation

\section{Introduction}

In India, "older adults" are defined as individuals aged $\geq 60$ years, accounting for $8.6 \%$ of the country's population. ${ }^{1}$ It is expected that the proportion of the older population will increase to $11 \%$ by 2025 and $19 \%$ by $2050 .{ }^{2}$ Falls are a leading public health issue in the older adults. ${ }^{3,4}$ In the Indian population, the prevalence of falls among elderly was between $14 \%$ and $53 \%{ }^{5,6}$ In a previous study, the prevalence of fall-related injuries in elderly in developing countries ranged from $1.0 \%$ to $6.6 \% .^{7}$ Falls can influence psychological functioning, which causes increased fear of falling (FOF). ${ }^{8}$

Several scales and tests, including activities-specific balance confidence (ABC) scale, have been developed for screening the risks of fall and tested in the elderly population..$^{9-14}$ The ABC scale is an instrument developed in English language that measures FOF. Huang and Wang $^{15}$ reported a strong internal consistency reliability 
of the ABC scale in community-dwelling elderly. Similarly, Talley et $\mathrm{al}^{16}$ reported a strong internal consistency reliability and validity of the ABC scale in older women. Myers et $\mathrm{al}^{17}$ investigated the discriminative and assessment qualities of the $\mathrm{ABC}$ scale and reported that the scale is able to distinguish between older adults at various levels of functional mobility. Beninato et a ${ }^{18}$ reported that the $\mathrm{ABC}$ scale was most accurate in identifying individuals with risk of multiple falls. In addition, Lajoie and Gallagher ${ }^{19}$ and Pang et $\mathrm{al}^{20}$ found associations between the ABC scale and risk of falls in older adults and in people with stroke, respectively.

The use of a self-administered scale in a native language would make research and the clinical management more effective. Recently, the ABC scale was adapted into various languages and cultures. ${ }^{21,22}$ Good intra- and interrater reliabilities were reported for the Brazilian-Portuguese adaptation and translation of the ABC scale for the Brazilian population. ${ }^{21}$ Similarly, the Chinese Mandarin adaptation of the ABC scale was found to be reliable and valid for the evaluation of balance confidence in the elderly population in mainland China. ${ }^{22}$ More recently, Moiz et $\mathrm{al}^{23}$ had reported the psychometric properties of the cross-culturally adapted Hindi version of the ABC scale (ABC-H). This study aimed to examine the ability of the ABC-H scale to discriminate between fallers and non-fallers and to examine its predictive validity for prospective falls.

\section{Materials and methods Subjects}

A sample of 125 subjects, aged 60-86 years, who could read and communicate in Hindi participated. The subjects included neighborhood older individuals, university employees, and patients' attendants at the physiotherapy clinic at Jamia Millia Islamia, New Delhi, India. Patients who received physiotherapy regimen or those with a history of psychotic and cognitive problems were excluded. All subjects gave their written informed consent. The institutional human ethics committee of Jamia Millia Islamia approved the study (JMI/IEC-1210/2011).

\section{$\mathrm{ABC}-\mathrm{H}$ scale}

The ABC-H has been proposed as an alternative balance confidence measure in Hindi-knowing Indian older adults. The ABC-H scale is a self-reported questionnaire providing information on balance confidence in the performance of 16 different daily activities, such as stair climbing, walking in the house, and walking on slippery floors. The questionnaire contains 16 items scored on a range from $0 \%$ to $100 \%$ (0 indicating no confidence and 100 indicating full confidence). Its cross-cultural adaptation, validity, and reliability in the elderly population have been established. ${ }^{21}$ The total ABC scale score of $\leq 67$ in the original English version indicates an increased risk of fall. ${ }^{19}$ All the subjects were requested to answer the questionnaire of the $\mathrm{ABC}-\mathrm{H}$ scale as reported previously. ${ }^{23}$

\section{Prospective fall assessment}

The number of falls over the 12-month follow-up period was collected using the monthly mailed "fall calendars" printed on postcards (12 diaries per participant; Figure 1). The participants were advised to record all falls in this calendar and return it back by mail at the end of each month. The participants who indicated falls in a given month were contacted and interviewed to obtain details about the falls recorded. Individuals were grouped as "fallers" if they reported one or more falls and as "non-fallers" if they had no incidence of falls. A faller was characterized as "an individual who has fallen at least once in a given time period". ${ }^{24}$ The definition of fall in this study was "any event when the resident unintentionally comes to rest on the floor regardless of the cause". 25

\section{Other measurements}

Sociodemographic and clinical data including the total ABC-H score, age, sex, height, weight, body mass index (BMI), educational level, cognitive ability (using the Mini Mental State Examination), use of walking aids, marital status, and number of comorbidities and medications were measured at baseline.

\section{Sample size estimation}

Sample size estimation for logistic regressions is a compound problem. ${ }^{26}$ Sample size was determined using the formula

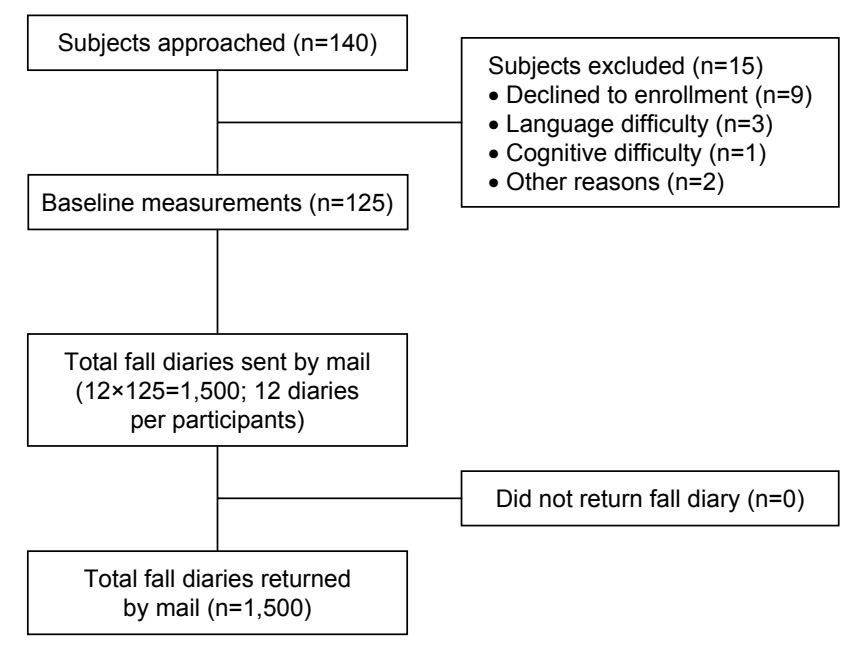

Figure I Flow chart showing the number of fall diaries sent and retrieved. 
$\mathrm{n}=10 \mathrm{k} / \mathrm{p}$, suggested by Peduzzi et al, ${ }^{26}$ where $\mathrm{p}$ is the smallest of the proportions of positive or negative cases in the population. According to Joshi et al, ${ }^{27}$ who found a prevalence of falls of (p) $51.5 \%$, and $\mathrm{k}$ is the number of covariates (in our study, six independent variables were used). The calculated sample size was 117 , and by adding the expected loss, it would be at least 125 .

\section{Data analyses}

Descriptive statistics, discriminative validity, and logistic regression analyses were conducted using SPSS 21.0. Discriminative validity was investigated by analyzing the total $\mathrm{ABC}-\mathrm{H}$ scale scores between the faller and non-faller groups using an independent $t$-test. The ABC-H scale scores of the fallers were expected to be significantly lower than those of the non-fallers. The Med Calc version 13.1.0 (MedCalc Soft., Ostend, Belgium) statistical software was used for analyzing the diagnostic validity indices. The fall diaries served as the tool to categorize the fallers and non-fallers during the 1-year follow-up period. The continuous and dichotomous total ABC-H scale scores of $\geq 58.13$ and $\leq 58.13$, respectively, were the test variables. Sensitivity, specificity, Youden index J, area under the curve (AUC), positive and negative likelihood ratios ( $\mathrm{LR}+$ and $\mathrm{LR}-$ ), and positive and negative predictive values (PPV and NPV) were calculated to investigate the predictive ability of the $\mathrm{ABC}-\mathrm{H}$ scale. The percentage test accuracy (specificity + sensitivity/2), and the false-positive (100 - specificity) and false-negative rates (100 - sensitivity) were calculated manually.

Besides, the logistic regression analysis was performed. The total ABC-H scale score was used as a dichotomous and continuous variable according to the cutoff value selected in the receiver operating characteristic (ROC) curve analysis. First, the odds ratios (ORs) with 95\% confidence intervals (95\% CIs) were calculated for the ABC-H scale score and other variables at baseline for prospective fall risks using the unadjusted logistic regression. Subsequently, the multivariable logistic regression model was used controlling for age, sex, and the variables significant in the unadjusted logistic regression models to calculate the ORs with 95\% CIs for the continuous and dichotomous $\mathrm{ABC}-\mathrm{H}$ scale scores for the independent prospective fall risk. A $P$-value $<0.05$ was considered statistically significant.

\section{Results}

The mean age and the mean BMI were $70.4 \pm 6.39$ years and $23.65 \pm 2.92 \mathrm{~kg} / \mathrm{m}^{2}$, respectively. Eighty-eight men participated in the study. The demographic attributes of the subjects are shown in Table 1.

\section{Discriminant validity}

The total ABC-H scale scores of the fallers $(n=22)$ and the non-fallers ( $\mathrm{n}=103)$ were significantly contrast. As expected, the mean total ABC-H scale score of the fallers was significantly below the score of the non-fallers $(52.6 \pm 8.1$ vs $73.1 \pm 12.2 ; P<0.001)$.

\section{ROC curve analysis}

The results from the ROC curve analysis (Figure 2), Youden index J, LR+, LR-, PPV, NPV, test accuracy, and falsepositive and negative rates are shown in Table 2. Based on the Youden index $\mathrm{J}$ and the coordinates of the ROC curve, a cutoff value of the total ABC-H scale score of $\leq 58.13$ was proposed for the fallers. With this cutoff value, the ABC-H scale had a sensitivity of $86.36 \%$, specificity of $87.38 \%$, PPV of $59.4 \%$, and NPV of $96.8 \%$ (Table 2). The ABC-H scale exhibited a good overall accuracy in identifying subjects with a history of fall with an excellent AUC (AUC $=0.91)$.

In this study, there were 22 fallers and $19(86 \%)$ had a true-positive test result for the fall. By contrast, 103 were non-fallers; however, $13(12.6 \%)$ had a false-positive test result. The LR+ and LR- were 6.8 and 0.16 , respectively. Individuals with falls had seven times more possibility to have a positive test result, compared to those who had no prospective fall in 1 year. Three of the 22 fallers $(13.6 \%)$ had a false-negative test result, whereas 90 of the 103 non-fallers $(87.3 \%)$ had a true-negative test result. The ABC-H scale correctly predicted whether subjects would fall over 1 year in 109 out of the 125 participants at baseline (test accuracy $=87.2 \%$ ).

\section{Logistic regression analysis}

The univariate logistic regression models exhibited a lower performance in the ABC-H scale, higher number of comorbidities and medications, and two falls at baseline in the past year, which were significantly related with falling during the 1-year follow-up period (Table 3). Specifically, each percent decrease in the total $\mathrm{ABC}-\mathrm{H}$ scale score was related with $83 \%$ increased odds of future falls, and those with a dichotomized total ABC-H scale score $\leq 58.13 \%$ were 0.02 times more likely to have future falls than those with a total ABC-H scale score $\geq 58.13 \%$.

The multivariable logistic regression models controlled for age, sex, BMI, number of comorbidities and medications, and two falls in the past year were used to determine the ORs for the diagnostic values of the total ABC-H scale score (Table 4). Each percent increase in the total ABC-H scale score was independently and significantly related with increased risk of future falls (model 1: OR $=0.84,95 \%$ 
Table I Baseline characteristics of total sample, fallers, and non-fallers

\begin{tabular}{|c|c|c|c|c|}
\hline Descriptive variables & Total $(\mathbf{N}=125)$ & Fallers $(n=22)$ & Non-fallers $(n=103)$ & $P$-value \\
\hline$A B C-H$ score & $69.5 \pm 14$ & $52.64 \pm 8.1$ & $73.10 \pm 12.2$ & $<0.00 I^{*}$ \\
\hline Age & $70.2 \pm 6.39$ & $74.09 \pm 5.6$ & $69.47 \pm 6.2$ & $0.002 *$ \\
\hline \multicolumn{5}{|l|}{ Age groups, n (\%) } \\
\hline $60-65$ & $26(20.8)$ & $2(9.1)$ & $24(23.3)$ & $0.058^{\dagger}$ \\
\hline $65-69$ & $30(24.0)$ & $2(9.1)$ & $28(27.2)$ & \\
\hline $70-74$ & $31(24.8)$ & $6(27.3)$ & $25(24.3)$ & \\
\hline $75-79$ & $27(21.6)$ & $6(27.3)$ & $21(20.4)$ & \\
\hline $80+$ & II (8.8) & $6(27.3)$ & $6(5.8)$ & \\
\hline \multicolumn{5}{|l|}{ Sex, n (\%) } \\
\hline Males & 88 (70.4\%) & $10(45.5 \%)$ & 78 (75.7\%) & $<0.005^{\dagger}$ \\
\hline Females & 37 (29.6\%) & $12(54.5 \%)$ & $25(24.3 \%)$ & \\
\hline Height $(\mathrm{cm})$ & $164.3 \pm 5.8$ & $162.4 \pm 5.7$ & $164.7 \pm 5.7$ & $0.09 *$ \\
\hline Weight (kg) & $64.3 \pm 7.2$ & $62.7 \pm 7.6$ & $64.7 \pm 7.7$ & $0.26 *$ \\
\hline Body mass index $\left(\mathrm{kg} / \mathrm{m}^{2}\right)$ & $23.8 \pm 2.7$ & $23.7 \pm 2.3$ & $23.8 \pm 2.8$ & $0.82^{*}$ \\
\hline \multicolumn{5}{|l|}{ Education, n (\%) } \\
\hline Elementary & $57(45.6)$ & II (50.0) & $46(44.7)$ & $0.619^{\dagger}$ \\
\hline Secondary & $30(24.0)$ & $2(9.1)$ & $28(27.2)$ & \\
\hline Senior secondary & $30(24.0)$ & $8(36.4)$ & $22(21.4)$ & \\
\hline College & $8(6.4)$ & I (4.5) & $7(6.8)$ & \\
\hline MMSE & $23.9 \pm 18.9$ & $21.3 \pm 2.2$ & $24.5 \pm 20.8$ & $0.472 *$ \\
\hline Use of waking aid, n (\%) & $4(3.2)$ & $3(13.6)$ & I (0.97) & $<0.00 \mathrm{I}^{\dagger}$ \\
\hline \multicolumn{5}{|l|}{ Marital status, n (\%) } \\
\hline Never married & $3(2.4)$ & $0(0)$ & $3(2.9)$ & $0.917^{\dagger}$ \\
\hline Married & $108(86.4)$ & $21(95.5)$ & $87(84.5)$ & \\
\hline Widowed & $12(9.6)$ & $\mathrm{I}(4.5)$ & II (I0.7) & \\
\hline Divorced/separated & $2(1.6)$ & $0(0)$ & $2(1.9)$ & \\
\hline Number of comorbidities & $0.54 \pm 0.88$ & $1.55 \pm 1.05$ & $0.32 \pm 0.6$ & $<0.00 \mathrm{I}^{\dagger}$ \\
\hline Number of medications & $0.50 \pm 0.88$ & $1.64 \pm 1.0$ & $0.26 \pm 0.6$ & $<0.00 \mathrm{I}^{\dagger}$ \\
\hline Any falls in previous year, $\mathrm{n}(\%)$ & $22(17.6)$ & $14(63.6)$ & $8(7.8)$ & $<0.00 \mathrm{I}^{\dagger}$ \\
\hline Two falls in previous year, $\mathrm{n}(\%)$ & $8(6.4)$ & $7(31.0)$ & $\mathrm{I}(1.0)$ & $<0.00 \mathrm{I}^{\dagger}$ \\
\hline
\end{tabular}

Notes: Values are mean \pm standard deviation, unless otherwise indicated. *Independent $t$-test, †Pearson's chi-squared test.

Abbreviations: $A B C-H$, Hindi version of activities-specific balance confidence; MMSE, mini-mental status examination; SD, standard deviation.

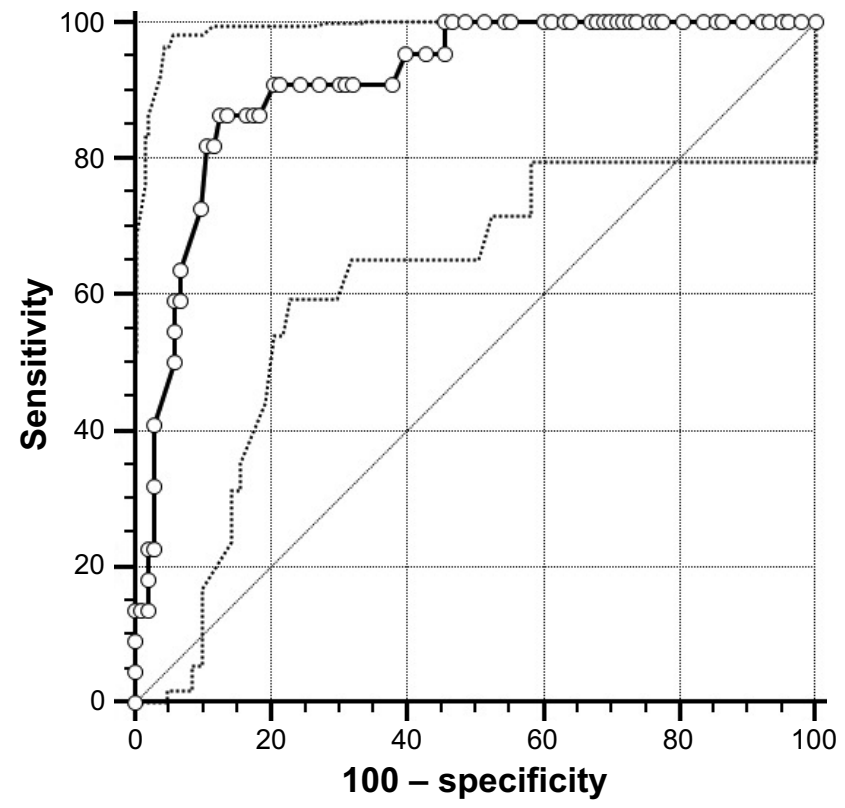

Figure 2 Receiver operating curve analysis for the ability of the Hindi version of activities-specific balance confidence scale to distinguish between fallers and nonfallers $(A \cup C=0.91)$.

Abbreviation: AUC, area under the curve.
$\mathrm{CI}=0.75-0.96, P=0.009$; Table 4). A dichotomized total ABC-H scale score with a cutoff value of $\leq 58.13 \%$ was also related with the odds of future falls, adjusted for age, sex, number of comorbidities and medications, and two falls in

Table 2 Diagnostic and predictive values of $A B C-H$ scale

\begin{tabular}{ll}
\hline Parameters & Values \\
\hline Area under the curve $(95 \% \mathrm{Cl})$ & $0.9 \mathrm{I}(0.84-0.95)$ \\
Cutoff score & 58.13 \\
Youden index Ja & $0.73(0.57-0.86)$ \\
Sensitivity $(95 \% \mathrm{Cl})$ & $86.36 \%(65.1-97.1)$ \\
Specificity $(95 \% \mathrm{Cl})$ & $87.38 \%(79.4-93.1)$ \\
LR+ $(95 \% \mathrm{Cl})$ & $6.8(5.7-8.2)$ \\
LR- $(95 \% \mathrm{Cl})$ & $0.16(0.05-0.5)$ \\
Positive predictive value $(95 \% \mathrm{Cl})$ & $59.4 \%(40.6-76.3)$ \\
Negative predictive value $(95 \% \mathrm{Cl})$ & $96.8 \%(90.8-99.3)$ \\
Test accuracy & $87.2 \%$ \\
False-positive rate & $12.2 \%$ \\
False-negative rate & $13.6 \%$ \\
\hline
\end{tabular}

Notes: ${ }^{a}$ The maximum vertical distance between ROC curve and diagonal line. $\mathrm{J}=$ sensitivity $-(\mathrm{I}-$ specificity). Value is (range, $0-I)$.

Abbreviations: $\mathrm{ABC}-\mathrm{H}$, Hindi version of activities-specific balance confidence; $\mathrm{Cl}$, confidence interval; LR+, positive likelihood ratio; LR-, negative likelihood ratio. 
Table 3 Univariate logistic regression models predicting fall during the I-year follow-up

\begin{tabular}{lll}
\hline Variables & Odds ratio $(95 \% \mathrm{CI})$ & $P$-value \\
\hline ABC-H (continuous) & $0.83(0.77-0.90)$ & $<0.00 \mathrm{I}$ \\
$\mathrm{ABC}-\mathrm{H} \leq 58.13$ & $0.02(0.00-0.08)$ & $<0.00 \mathrm{I}$ \\
Age & $\mathrm{I} .13(\mathrm{I} .04-1.22)$ & 0.003 \\
Female sex & $0.26(0.10-0.69)$ & 0.007 \\
Body mass index & $0.98(0.82-1.16)$ & 0.82 \\
Number of comorbidities & $3.90(2.24-6.80)$ & $<0.00 \mathrm{I}$ \\
Number of medications & $4.73(2.6 \mathrm{I}-8.56)$ & $<0.00 \mathrm{I}$ \\
Any fall in previous year & $0.048(0.16-0.14)$ & $<0.00 \mathrm{I}$ \\
Two falls in previous year & $0.21(0.02-0.183)$ & $<0.00 \mathrm{I}$ \\
\hline
\end{tabular}

Abbreviations: $A B C-H$, Hindi version of activities-specific balance confidence; $\mathrm{Cl}$, confidence interval.

the past year $($ model $2: \mathrm{OR}=0.032,95 \% \mathrm{CI}=0.004-0.25$, $P=0.001)$.

\section{Discussion}

This study examined whether the recently translated selfreported balance confidence scale $(\mathrm{ABC}-\mathrm{H})$ predicted future falling in Indian older adults. In this study, the prospective faller group had significantly lower total ABC-H scale scores than the non-faller group, which indicates that people with a prospective fall are more affected by the FOF complex; therefore, they are more restricted in their daily activities. In a previous study, Lajoie and Gallagher reported a total score of 48 and 85 for fallers and non-fallers, respectively, using the original ABC scale. ${ }^{19}$ Similarly, in this study, the total ABC-H scale scores of the fallers and non-fallers were 52.6 and 73.1, respectively. However, Powell and Myers reported a total score of 53.7 and 67.7 for the fallers and non-fallers, respectively. ${ }^{12}$

The result of the ROC analysis was used to determine sensitivity and specificity. The primary aim of this study was to identify an optimal cutoff value that would indicate as many fallers as possible as true positives and older adults without prospective falls (non-fallers) as true negatives. In this study, the optimal cutoff value of the total $\mathrm{ABC}-\mathrm{H}$ scale score was $\leq 58.13$ for distinguishing between the fallers and non-fallers in the elderly Indian population. Our cutoff value is slightly lower than that reported by Lajoie and Gallagher in the elderly using the original ABC scale (total score $\leq 67 \%$ ) in a Canadian population. ${ }^{19}$ There was no agreement about the general cutoff value for the $\mathrm{ABC}$ scale to accurately indicate those at high risk of future falls. Moreover, a variety of cutoff values were suggested for the different diseases. Mak and Pang ${ }^{28}$ reported a cutoff value of $<69 \%$ in Parkinson's disease. ${ }^{28}$ Furthermore, Beninato et $\mathrm{al}^{18}$ had suggested that a cutoff value of 81.1 in patients with stroke can provide a relative certainty that the individual did not have a history of multiple falls.

In this study, the ABC-H scale correctly identified the number of fallers and non-fallers with sensitivity and specificity values of $86 \%$ and $87 \%$, respectively. Similarly, in a cross-sectional study of older individuals living in a Canadian community, Lajoie and Gallagher ${ }^{19}$ reported that the original $\mathrm{ABC}$ scale correctly classified the fallers and non-fallers with sensitivity and specificity values of $84 \%$ and $87 \%$, respectively. In this study, the ROC curve showed that the AUC for the outcomes of falls was 0.91; this indicates that the $\mathrm{ABC}-\mathrm{H}$ scale provides a good predictive accuracy in screening the outcomes of falls in older adults. A previous study reported that an AUC of 0.8 represents a reasonably effective model..$^{29}$ In this study, the Youden index J was 0.73 , which is a summary statistics of the ROC curves used to evaluate the performance of a diagnostic test. ${ }^{30}$ It measures the effectiveness of a predictive scale and enables the selection of an optimal threshold value (cutoff) for the scale. Its value ranges from 0 (indicates uninformative tests) to

Table 4 Multivariable logistic regression models predicting falls during the I-year follow-up

\begin{tabular}{|c|c|c|c|c|}
\hline \multirow[t]{2}{*}{ Variables } & \multicolumn{2}{|l|}{ Model I } & \multicolumn{2}{|l|}{ Model 2} \\
\hline & Odds ratio $(95 \% \mathrm{Cl})$ & $P$-value & Odds ratio $(95 \% \mathrm{Cl})$ & $P$-value \\
\hline ABC-H (continuous) & $0.84(0.75-0.96)$ & 0.009 & - & - \\
\hline$A B C-H \leq 58.13$ & - & - & $0.032(0.004-0.25)$ & 0.001 \\
\hline Age & $0.91(0.76-1.08)$ & 0.28 & $0.96(0.81-1.14)$ & 0.68 \\
\hline Female sex & $0.56(0.12-2.49)$ & 0.44 & $0.61(0.12-2.97)$ & 0.54 \\
\hline Body mass index & $0.91(0.67-1.24)$ & 0.57 & $0.89(0.65-1.23)$ & 0.49 \\
\hline Number of comorbidities & $5.15(0.44-6.04)$ & 0.59 & $0.34(0.25-4.68)$ & 0.42 \\
\hline Number of medications & $6.97(0.65-74.0)$ & 0.10 & II.57 (0.86-154.13) & 0.64 \\
\hline Any fall in previous year & $0.83(0.11-5.84)$ & 0.70 & $1.22(0.17-8.58)$ & 0.83 \\
\hline Two falls in previous year & $0.53(0.21-13.8)$ & 0.70 & $0.23(0.14-3.88)$ & 0.30 \\
\hline
\end{tabular}

Note: Continuous ABC-H percentage was used in model I and dichotomous ABC-H with the cutoff point of 58 . $13 \%$ was used in model 2 , both controlling for age, sex, body mass index, number of comorbidities and medications, and two falls in the previous year.

Abbreviations: $\mathrm{ABC}-\mathrm{H}$, Hindi version of activities-specific balance confidence; $\mathrm{Cl}$, confidence interval. 
1 (indicates perfect tests). No previous study reported the Youden index $\mathrm{J}$ for the ABC scale.

In this study, the PPV and NPV showed acceptable levels in classifying individuals who reported a fall at the given cutoff values. PPV is the percentage of subjects with positive test results who had prospective falls. NPV is the percentage of subjects with negative test results who had no incidence of fall. ${ }^{31}$ In this study, the PPV was low (59.4\%) and the NPV was high (96.4\%), which indicates accuracy of the test. The diagnostic values of the test usually depend on the prevalence of the condition in the individuals being tested. ${ }^{31}$ In the presence of a very low prevalence of the disease, the PPV will not be close to 1 , even though both the specificity and sensitivity are high. ${ }^{31}$ A standardized approach has been suggested, where the PPV is normalized to a sensitivity prevalence of $50 \% .{ }^{32}$ In this study, the nonfaller group had a higher proportion $(n=103)$ than the faller group ( $n=22)$; therefore, the PPV was low and the NPV was high. If all participants had a history of fall, the PPV and NPV would be $100 \%$ and $0 \%$, respectively. Moreover, in this study, the LR+ was 6.8 , indicating that people with a score below $58.13 \%$ are seven times more prone to have a fall than those with higher scores.

A previous study indicated that the ORs of the total ABC scale score of -0.041 and that of the $\mathrm{ABC}$ question of -0.071 were important predictors of fall. ${ }^{19}$ This means that the $\mathrm{ABC}$ scale score was related with a $4 \%-5 \%$ greater risk of future falls. The higher risks of future falls demonstrated in this study may be associated with the use of rigorous fall monitoring system using fall diaries than with the reaction time, Berg score and the mean ABC score used as predictors in the past study.

A good-quality data of the fall incidence was the major strength of this study. To identify prospective fall, a fall diary was used, which was recorded by each participant on a daily basis and submitted at the end of each month, in addition to follow-up telephone calls as required. This type of vigorous monitoring system was effective in reducing recall bias. ${ }^{33}$

This study had some potential limitations. It is limited to only healthy older adults. Participants with neurologic disorders or musculoskeletal disorders of lower extremities might respond differently. Although the ABC-H scale was able to assess balance confidence, it may not be exhaustive enough to include other fall risk components, such as intrinsic and environmental factors. Furthermore, the small prevalence of the fallers in this study may be attributed to the inadequate sample size; therefore, these results must be interpreted with caution. Future studies must use a larger sample size for better prediction of the occurrence of falls.

\section{Conclusion}

The results provide a strong support for establishing the use of the ABC-H scale as a predictive tool for correctly identifying elderly individuals more susceptible to falls. This would allow health care professionals to screen those with a substantial risk of falling and enroll them in a fall prevention training program.

\section{Acknowledgment}

The authors are grateful to the Deanship of Scientific Research, King Saud University for funding through Vice Deanship of Scientific Research Chairs.

\section{Disclosure}

The authors report no conflicts of interest in this work.

\section{References}

1. Jeyalakshmi S, Chakrabarti S, Gupta N. Situation analysis of the elderly in India. Central Statistics Office, Ministry of Statistics and Programme Implementation, Government of India document 2011. Available from: http://mospi.nic.in/sites/default/files/publication_reports/elderly_in_ india.pdf. Accessed December 24, 2016.

2. United Nations. World population prospects: The 2012 revision. New York, NY: United Nations Department of economic and social affairs, Population Division 2012. Available from: http://esa.un.org/wpp/ documentation/pdf/wpp2012_highlights.pdf. Accessed June 8, 2015.

3. El-Khoury F, Cassou B, Charles MA, Dargent-Molina P. The effect of fall prevention exercise programmes on fall induced injuries in community dwelling older adults: systematic review and meta-analysis of randomised controlled trials. BMJ. 2013;347:f6234.

4. Gazibara T, Kurtagic I, Kisic-Tepavcevic D, et al. Falls, risk factors and fear of falling among persons older than 65 years of age. Psychogeriatrics. In press January 27, 2017.

5. Krishnaswamy B, Usha G. Falls in older people. Madras Medical College. Chennai 2003. Available from: http://www.who.int/ageing/ projects/SEARO.pdf. Accessed June 8, 2015.

6. Prakash O, Gupta LN, Singh VB, Singhal AK, Verma KK. Profile of psychiatric disorders and life events in medically ill elderly: experiences from geriatric clinic in Northern India. Int J Geriatr Psychiatry. 2007; 22(11):1101-1105.

7. Stewart Williams J, Kowal P, Hestekin H, et al. Prevalence, risk factors and disability associated with fall-related injury in older adults in lowand middle-income countries: results from the WHO Study on global AGEing and adult health (SAGE). BMC Med. 2015;13:147.

8. Young WR, Mark Williams A. How fear of falling can increase fall-risk in older adults: applying psychological theory to practical observations. Gait Posture. 2015;41(1):7-12.

9. Nordin E, Lindelöf N, Rosendahl E, Jensen J, Lundin-Olsson L. Prognostic validity of the Timed Up-and-Go test, a modified Get-Up-and-Go test, staff's global judgment and fall history in evaluating fall risk in residential care facilities. Age Ageing. 2008;37(4):442-448.

10. Scott V, Votova K, Scanlan A, Close J. Multifactorial and functional mobility assessment tools for fall risk among older adults in community, home-support, long-term and acute care settings. Age Ageing. 2007;36(2): $130-139$. 
11. Russell MA, Hill KD, Day LM, Blackberry I, Gurrin LC, Dharmage SC. Development of the Falls Risk for Older People in the Community (FROP-Com) screening tool. Age Ageing. 2009;38(1):40-46.

12. Powell LE, Myers AM. The activities-specific balance confidence (ABC) scale. J Gerontol A Biol Sci Med Sci. 1995;50(1):M28-M34.

13. Hachiya M, Murata S, Otao H, Kamijou K, Mizota K, Asami T. Reproducibility and validity of the 50-meter walking test in communitydwelling elderly. J Phys Ther Sci. 2015;27(5):1511-1514.

14. Hachiya M, Murata S, Otao H, Ihara T, Mizota K, Asami T. Usefulness of a 50-meter round walking test for fall prediction in the elderly requiring long-term care. J Phys Ther Sci. 2015;27(12):3663-3666.

15. Huang TT, Wang WS. Comparison of three established measures of fear of falling in community-dwelling older adults: psychometric testing. Int J Nurs Stud. 2009;46(10):1313-1319.

16. Talley K, Wyman J, Gross C. Psychometric properties of the activitiesspecific balance confidence scale and the survey of activities and fear of falling in older women. J Am Geriatr Soc. 2008;56(2):328-333.

17. Myers AM, Fletcher PC, Myers AH, Sherk W. Discriminative and evaluative properties of the Activities-specific Balance Confidence (ABC) Scale. J Gerontol A Biol Sci Med Sci. 1998;53(4):M287-M294.

18. Beninato M, Portney LG, Sullivan PE. Using the international classification of functioning, disability and health as a framework to examine the association between falls and clinical assessment tools in people with stroke. Phys Ther. 2009;89(8):816-825.

19. Lajoie Y, Gallagher SP. Predicting falls within the elderly community: comparison of postural sway, reaction time, the Berg balance scale and the Activities-specific Balance Confidence (ABC) scale for comparing fallers and non-fallers. Arch Gerontol Geriatr. 2004;38(1):11-26.

20. Pang M, Eng J, Miller W. Determinants of satisfaction with community reintegration in older adults with chronic stroke: role of balance selfefficacy. Phys Ther 2007;87(3):282-291.

21. Marques AP, Mendes YC, Taddei U, Pereira CA, Assumpção A. BrazilianPortuguese translation and cross cultural adaptation of the activitiesspecific balance confidence (ABC) scale. Braz J Phys Ther. 2013; 17(2):170-178.
22. Guan Q, Han H, Li Y, Zhao L, Jin L, Zhan Q. Activities-specific Balance Confidence (ABC) scale adapted for the mainland population of China. Clin Rehabil. 2012;26(7):648-655.

23. Moiz JA, Bansal V, Noohu MM, Gaur SN, Hussain ME. Cross-cultural adaptation and psychometric analysis of the hindi-translated activitiesspecific balance confidence Scale. Middle East J Rehabil Health. 2016; 3(1):e34886

24. Rogmark C, Sernbo I, Johnell O, Nilsson JA. Incidence of hip fractures in Malmo, Sweden, 1992-1995. A trend-break. Acta Orthop Scand. 1999; 70(1):19-22.

25. Jensen J, Lundin-Olsson L, Nyberg L, Gustafson Y. Falls among frail older people in residential care. Scand J Public Health. 2002;30(1):54-61.

26. Peduzzi P, Concato J, Kemper E, Holford TR, Feinstein AR. A simulation study of the number of events per variable in logistic regression analysis. J Clin Epidemiol. 1996;49(12):1373-1379.

27. Joshi K, Kumar R, Avasthi A. Morbidity profile and its relationship with disability and psychological distress among elderly people in Northern India. Int J Epidemiol. 2003;32(6):978-987.

28. Mak MK, Pang MY. Fear of falling is independently associated with recurrent falls in patients with Parkinson's disease: a 1-year prospective study. J Neurol. 2009;256(10):1689-1695.

29. Haynes RB, Sackett DL, Guyatt GH, Tugwell P. Clinical Epidemiology: How To Do Clinical Practice Research. 3rd ed. Philadelphia, PA: Lippincott Williams \& Wilkins; 2006.

30. Ruopp MD, Perkins NJ, Whitcomb BW, Schisterman EF. Youden Index and optimal cut-point estimated from observations affected by a lower limit of detection. Biom J. 2008;50(3):419-430.

31. Altman DG, Bland JM. Diagnostic tests 2: predictive values. $B M J$ 1994;309(6947):102.

32. Heston TF. Standardizing predictive values in diagnostic imaging research. J Magn Reson Imaging. 2011;33(2):505; author reply 506-507.

33. Ganz DA, Higashi T, Rubenstein LZ. Monitoring falls in cohort studies of community-dwelling older people: effect of the recall interval. $\mathrm{J} \mathrm{Am}$ Geriatr Soc. 2005;53(12):2190-2194.
Clinical Interventions in Aging

\section{Publish your work in this journal}

Clinical Interventions in Aging is an international, peer-reviewed journal focusing on evidence-based reports on the value or lack thereof of treatments intended to prevent or delay the onset of maladaptive correlates of aging in human beings. This journal is indexed on PubMed Central, MedLine,

\section{Dovepress}

CAS, Scopus and the Elsevier Bibliographic databases. The manuscript management system is completely online and includes a very quick and fair peer-review system, which is all easy to use. Visit http://www.dovepress. com/testimonials.php to read real quotes from published authors. 